\title{
European Academy of Paediatric Dentistry guideline production
}

\author{
K. J. Toumba ${ }^{1}$
}

Published online: 1 February 2016

(C) European Academy of Paediatric Dentistry 2016

One of the important functions of the European Academy of Paediatric Dentistry (EAPD) is to produce guidelines on important topics of paediatric dentistry. These guidelines are freely available online at the EAPD website (http:// www.eapd.eu) to EAPD members, paediatric dentistry specialists from all over the world, general dental practitioners and of course to parents and the general public. Guidelines help both dentists and the public on important topics in dentistry by presenting the evidence for any recommendations, and where this is not possible expert opinion on good practice points are given.

The production of EAPD guidelines is a lengthy process and takes place at the EAPD interim seminars and workshops, of which the latest guideline on "The management of early caries lesions in the primary and young permanent dentition" was framed during the ninth EAPD interim seminar and workshop in Brussels, Belgium, between 8 and 9 May 2015. The Belgium organising and scientific committees that included Professor Dominique Declerck, Professor Luc Marks, and Dr. Jeroen Vandenbulcke amongst others in conjunction with the EAPD clinical affairs committee chaired by Dr. Jan Kühnisch worked very hard and for a long time both before, during and after the interim seminar and workshop to ensure that the event was a great success and that the resulting guideline was evidenced based. The EAPD format for guideline production is that three important topics related to the guideline are presented by experts in the field at the interim seminar for all delegates. The experts prepare systematic reviews of their

K. J. Toumba

K.J.Toumba@leeds.ac.uk

1 Department of Paediatric Dentistry, University of Leeds School of Dentistry, Clarendon Way, Leeds LS2 9LU, UK topics beforehand and these are circulated to each of the selected workshop participants in advance of the workshop. The workshop participants are selected from each of the European member countries by the local EAPD councillors. Each of the three workshops has between 15 and 20 participants contributing to the discussions and production of the guideline in relation to their specific topics.

The three experts for this interim seminar and workshop were firstly Professor Kim Ekstrand (Copenhagen, Denmark) and Professor Iain Pretty (Manchester, UK) who spoke on "Detection and monitoring of early caries lesions". The second expert was Professor Svante Twetman (Copenhagen, Denmark) who spoke on "Caries-risk assessment in children-how accurate are we?" The third expert was Professor Cor van Loveren (Amsterdam, The Netherlands) who spoke on "Non-invasive methods". Following the presentations the workshop participants together with the invited experts had their group discussions whilst the other delegates had more lectures. The following day, the provisional guidelines were presented to all delegates.

The experts produced review papers which contributed to the topic guidelines and were submitted to the European Archives of Paediatric Dentistry for publication. Each of these review papers were peer reviewed in the normal way and when accepted appeared online until the guideline was ready for publication. The guideline had input from the experts, workshop participants and EAPD members as this was available for member's comments. In this special issue the completed guideline paper is the first article by Kühnisch et al. entitled "Best clinical practice guidance for management of early caries lesions in children and young adults-an EAPD policy document". The next three papers are the review papers related to the production of the guidelines. The second article in the issue is by Pretty and 
Ekstrand entitled "Detection and monitoring of early caries lesions-a review". The third article is by Twetman entitled "Caries-risk assessment in children-how accurate are we"? The fourth article is by van Loveren and van Palenstein Helderman entitled "Non-invasive caries treatment".

I hope that everyone enjoys reading the guidelines and the three review papers that resulted from the successful
Brussels interim seminar and workshop. The guidelines and review papers from previous interim seminars and workshops held in Istanbul, Turkey, in 2011 on pulp therapy and in Limmasol, Cyprus, in 2013 on interceptive orthodontics are in preparation for publication in future special issues of the European Archives of Paediatric Dentistry during 2016. 